\title{
LOS DESCAMPADOS DE PROMISIÓN DE LARA ALMARCEGUI
}

Data recepción: 2011/07/26

Data aceptación: 2012/10/12

Contacto autora: julia.ramirez.blanco@gmail.com
Julia Ramírez Blanco

Universidad Complutense de Madrid

\section{RESUMEN:}

Existe desde hace años toda una corriente de artistas que trabajan en torno al terrain vague, un espacio sin definir que evidencia las contradicciones urbanas. Frente a los numerosos creadores que intervienen en estos lugares vacíos, en el presente texto nos centramos en la obra de Lara Almarcegui, cuyos gestos sutiles, sin alterar la materialidad del territorio, cambian su contexto perceptivo. Tras analizar los distintos formatos a través de los cuales elabora su discurso, tratamos de comprender la propuesta urbana que se encuentra latente en su trabajo.

Palabras clave: Lara Almarcegui, post conceptualismo, terrain vague, intervenciones en el espacio público, teoría urbana.

\section{ABSTRACT:}

For a number of years now a great many artists have been developing their discourses around the terrain vague, an undefined space revealing urban contradictions. Though there are many creative minds operating in these empty spaces, we will focus in this text on the work of Lara Almarcegui, whose subtle gestures change the context in which we perceive the physical space, without actually altering the space itself. After analysing the various formats she uses to develop her discourse, we will seek to gain an understanding of the urban proposal latent in her work.

Keywords: Lara Almarcegui, post-conceptualism, terrain vague, public performances, urban theory.

\section{INTRODUCCIÓN}

Son, en definitiva, lugares externos, extraños, que quedan fuera de los circuitos, de las estructuras productivas. Son islas interiores vaciadas de actividad, son olvidos y restos que permanecen fuera de la dinámica urbana'.

El arquitecto Ignasi de Solá-Morales, autor de esta paradójica definición del terrain vague, afirma detectar "un interés creciente, casi una pasión" 2 por este tipo de espacios. Efectivamente, desde las artes plásticas y la arquitectura asistimos en los últimos años a una proliferación de discursos que giran en torno al descampado.
El vacío urbano parece atraer gran parte de los intereses de una generación marcada por la especulación inmobiliaria, y por la dificultad para acceder a la vivienda que ésta genera ${ }^{3}$. El terrain vague, producido por el sistema constructivo, constituye un territorio paradójico en su vacío e inutilidad. Otro arquitecto, Luc Lévesque, destaca cómo las posturas se suelen polarizar en dos visiones contrapuestas, que representan la oposición binaria entre los partidarios del orden y los amantes del caos.

Para algunos, los solares constituyen zonas de marginalidad y deterioro; otros los perciben como entornos donde resulta posible la resistencia y el comportamiento liberador. Desde esta 
última perspectiva hablan numerosos creadores que sobre estos espacios indefinidos tratan de configurar territorios alternativos a la ciudad dominante. A pesar de ser muchos los que trabajan con estos lugares ${ }^{4}$, en el presente texto nos centramos en una sola artista, la española Lara Almarcegui, cuyo trabajo con los descampados muestra una particular coherencia, que aúna lo reflexivo y lo poético. Tras analizar su evolución y su desarrollo a través de tres formatos distintos (guías de terrenos vacíos, aperturas de descampados y preservación del terrain vague), trataremos de comprender la propuesta urbana que se encuentra implícita en su obra.

Almarcegui nace en Zaragoza en 1972 y estudia Bellas Artes entre 1991 y 1995 en la Universidad de Cuenca. Durante este período adquiere experiencia internacional, pasando un año en Lisboa y otro en Hamburgo. Más tarde, completa su formación en Nantes, desde donde se traslada a Ámsterdam. La artista comienza a exponer en momentos muy tempranos, adquiriendo un creciente reconocimiento: su obra ha podido verse en centros como el Witte de With Center de Róterdam, la Barbican Art Gallery de Londres o el Museo Reina Sofía de Madrid. Almarcegui ha participado también en diversas bienales como las de Liverpool (2004), São Paulo (2006), Sevilla (2006), Sharjah (2007), Gwangju (2008) o Taipei (2008 y 2010).

De su trabajo se desprende una fascinación persistente por los procesos de desaparición arquitectónica y sus legados materiales: demoliciones, ruinas, escombros. En concordancia con este interés, se sitúa su aproximación al descampado, un hueco que aparece periódicamente en la urbe contemporánea, como si fuera desvelado cuando se derriba un edificio. Durante más de una década, y "casi como en un programa" 5 , una parte importante de la producción de la artista gira en torno al terrain vague. Sin embargo, a diferencia de la mayor parte de creadores que se acercan a estos lugares, Almarcegui rehuye la idea de "re\|lenarlos" con algún elemento ajeno ${ }^{6}$.

En su concepción, añadir algo sería un proceder propio de la peor arquitectura: aquella que trata de construir sobre cualquier zona disponible. El solar aparece como un espacio valioso en sí mismo, sin que resulte necesario "instalar" nada en él. Empleando diversas estrategias artísticas que no cambian la materialidad del entorno, trata de alterar el contexto perceptivo del mismo, siguiendo la tradición duchampiana del ready made, que se amplía hacia el espacio ${ }^{7}$. El "terreno encontrado", previamente existente, es presentado ante el espectador con la intención de que sea apreciado de una manera distinta. ${ }^{8}$

\section{GUÍAS DEL HUECO}

En 1996, con veinticuatro años, Lara Almarcegui se traslada a Ámsterdam para estudiar en de Ateliers, un prestigioso centro de investigación artística gestionado por un grupo de creadores $^{9}$. Más allá del taller que allí se le ofrece, Lara se dedica a curiosear por los resquicios del edificio, entrando en áticos húmedos, habitaciones vacías y sótanos abandonados. Es así como surge la Guide to non delimitated rooms at de Ateliers $^{10}$ (Guía de los lugares no delimitados en "de Ateliers"), un subjetivo inventario que describe aquellas estancias deshabitadas que no tienen un uso preciso. Este pequeño cuaderno hecho de páginas fotocopiadas es dispuesto por su autora en la entrada de la escuela. A través de sus mapas y textos, ofrece una vivencia alternativa de la institución, en un recorrido por su espacio "inútil" (Fig. 1). Pese a que una gran pobreza de medios lo diferencia de obras posteriores, este trabajo seminal marca el comienzo de un corpus de publicaciones que reelabora el género de la guía ${ }^{11}$.

En 1999 Almarcegui publica bajo este formato su primera aproximación creativa al terrain vague, el Wastelands Map Amsterdam, a guide to the empty sites of the city ${ }^{12}$ (Mapa de descampados de Ámsterdam, una guía a los lugares vacíos de la ciudad). Aunque, por placer, ya visitaba solares antes de realizar esta obra ${ }^{13}$, es ahora cuando comienza a fotografiar y describir las parcelas vacías más interesantes de toda una ciudad. Al principio del libro, un mapa muestra la ubicación de los terrenos a los que se refieren las páginas siguientes (Fig. 2). Textos y hermosas fotografías en blanco y negro documentan cada uno de ellos, describiéndolos de manera individualizada, con un enorme cuidado.

Parece que el origen de estos trabajos se encuentra en las guías de arquitectura, que Almar- 


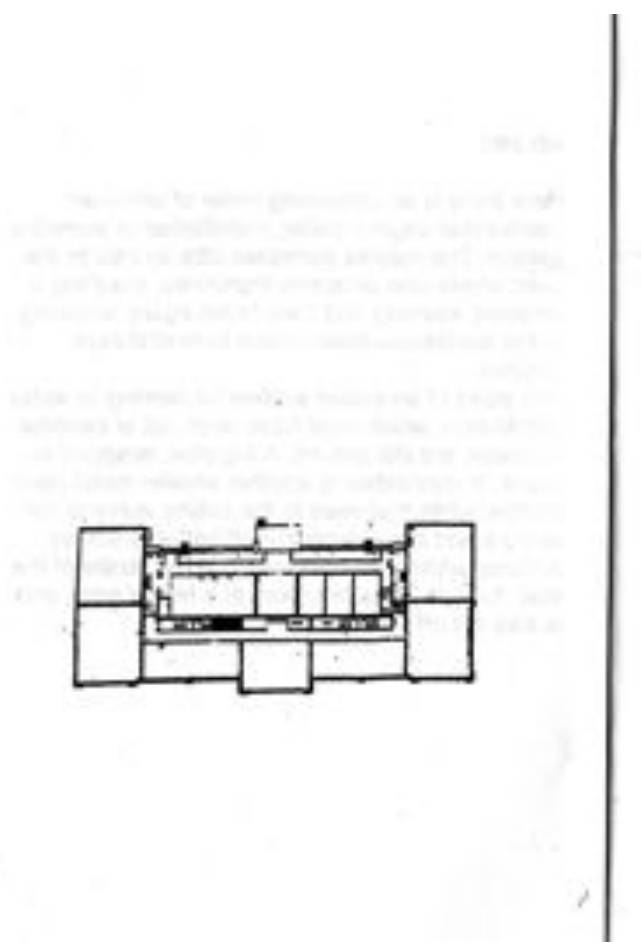

Fig. 1. Guía a los lugares indefinidos en de Ateliers, 1997.

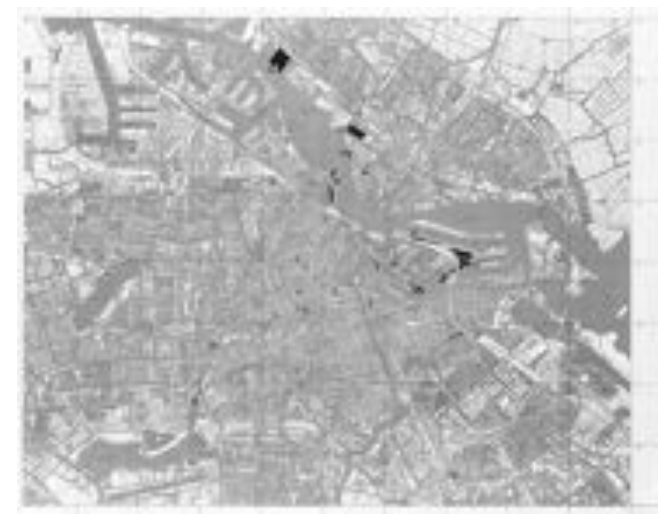

Fig. 2. Mapa de descampados de Ámsterdam, 1999

cegui decide hacer en negativo, cartografiando huecos en vez de construcciones ${ }^{14}$. Satisfecha con el funcionamiento del formato, lo utiliza de manera recurrente en los años que siguen, para retratar los solares de urbes tan dispares como Lund (2005) ${ }^{15}$, São Paulo (2006) ${ }^{16}$, Bilbao $(2008)^{17}$, Londres $(2009)^{18}$ o Nueva York $(2010)^{19}$.

\section{5en stic}

The best thing to do here is to get up on a chair and, by leaning against the wal, bok over 2 . You wil be able to see along under the roof. The view is of a dark space, an insulation cavity that stretches over all the fop floor rooms. Above this souce, another smaler rool sleces upwarts and above it yet ancther even smaller one. Esch one is connected to the next by a small flat space and each slopes at a more acute angle. This bulding is surprisingly reminiscent of a gothic cathedral.

The strangest thing about these attics is their total independence from visual conditions outside. They remain unchanged by blazing sunlight or weak daylight; they are always the same. 24 hours a day. at the year round. At the same time, they have a stronger connection with the weather than any other rooen these are chambers for feeing the city wath all the senses except sight.

También, en algunos casos, la autora analiza un único descampado, seleccionado por su singularidad o por su carácter especialmente efímero. Aunque la estructura de estas publicaciones presenta variaciones mínimas, cada lugar impone el sello único de sus propias peculiaridades ${ }^{20}$.

La edición de estos pequeños libros se concibe como una obra no comercial, y en su lectura se nos revela un curioso género literario, de carácter icónico-verbal. Cada una de las instantáneas brinda la contemplación estética de paisajes accidentales, normalmente despreciados o ignorados ${ }^{21}$. Percibimos en los solares elementos contrapuestos, que pertenecen a la vez al campo y a la ciudad, formando horizontes híbridos y paradójicos (Figs. 3 y 4). A través del conjunto de las imágenes, se siente el extraño poder de atracción de estos espacios, situados entre el abandono y la posibilidad. Al margen de lo escrito, el componente visual de estos pequeños libros permite una ojeada poética, una excursión imaginaria por los terrenos breves que genera el 


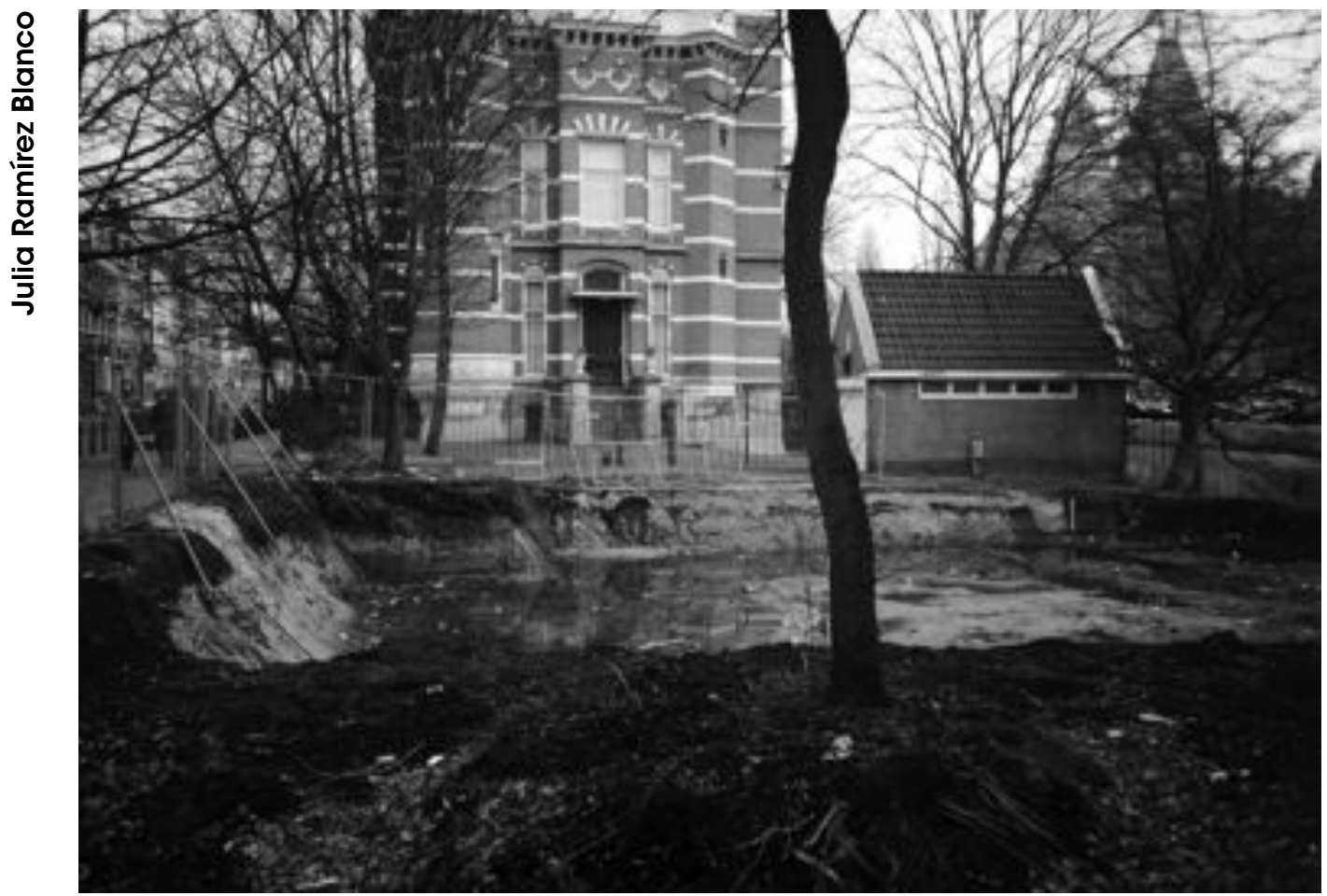

Fig. 3. Mapa de descampados de Ámsterdam, 1999.

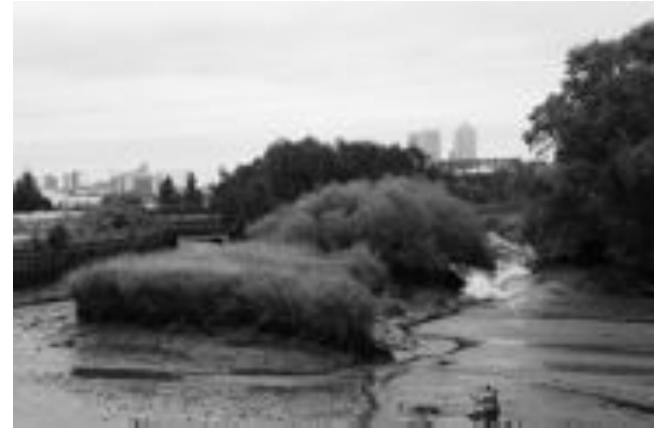

Fig. 4. Guía de descampados del valle del río de Lea, 2009.

paréntesis entre la demolición de un edificio y la construcción del siguiente.

\section{HISTORIAS DE SOLARES}

Los textos de las guías son el resultado de una esmerada investigación acerca de cada solar. En esta suerte de pequeñas biografías de la tierra, se nos narra la historia de cada parcela, enunciándose los distintos usos que le han dado sus antiguos y sus nuevos propietarios a lo largo del tiempo. Los relatos están llenos de cuestiones políticas: el nacimiento y la desaparición de los descampados nos remiten a los altibajos del desarrollo industrial, a las variables inversiones culturales o a los cambios en la especulación inmobiliaria. Almarcegui en sus escritos resalta también cómo estas modificaciones condicionan a su naturaleza, en forma de una vegetación salvaje que va reapareciendo según se instala el abandono.

Con el tiempo, los terrenos vacíos llegan a albergar ecosistemas propios, poblados por especies endémicas. Así, pueden llegar a conformar pequeñas reservas naturales en el corazón mismo de la urbe.

Las guías pretenden llamar la atención sobre aspectos positivos del hueco urbano:

presento los descampados como un lugar especial, una experiencia única, donde están 
sucediendo cosas que no suceden en el resto de la ciudad. (...) [H]ay una naturaleza, una vegetación, una libertad. Como un paraíso en cada terreno ${ }^{22}$.

Lara Almarcegui concibe las parcelas vacías como territorios edénicos, cotos de lo excepcional y lo maravilloso. Su amor por el paisaje abandonado es propio de una lectora entusiasta del "Tour por los monumentos de Passaic" de Robert Smithson ${ }^{23}$. Por otra parte, su insistencia en la autonomía que ofrece el descampado es el de una apasionada de aquel Henry David Thoreau que relata su retiro de dos años y dos meses en el bosque de Walden ${ }^{24}$. En sus escritos y declaraciones, la artista reitera su concepción del solar como espacio de libertad: si la utopía tradicional soñaba con la organización absoluta, para Almarcegui el buen lugar se encuentra en la indefinición y en la infinita posibilidad que ésta implica.

Las guías surgen como una exhortación a que otras personas disfruten del descampado. En estas publicaciones, el terrain vague se presenta como un sitio para la placentera visita: se propone un recorrido por otra ciudad dentro de la ciudad, la urbe de los huecos que nos ofrecen refugios de libertad. Y sin embargo, muchos de los terrenos retratados resultan inaccesibles de manera legal. En la poética de Almarcegui subyace la curiosidad humana por aquello que se adivina tras los muros. Late el impulso de entrar donde está prohibido hacerlo. Y la esperanza infantil de encontrar un paraíso cruzando una puerta cualquiera. Aunque la artista salta paredes y verjas, pronto empieza a desarrollar proyectos que posibilitan un acceso legal y colectivo. Comienza a buscar el permiso pertinente para poder pasar al otro lado.

\section{APERTURAS}

Aproximadamente a partir del año 2000 Almarcegui inicia una serie de obras que consisten "básicamente en abrir puertas" 25. La artista emprende un tipo de trabajo que parte de la negociación como método. El pacto con los propietarios de los solares se convierte en precondición necesaria para el desarrollo de un proyecto que no siempre resulta posible concluir:
(...) en Ámsterdam el ayuntamiento no me permitió abrir un descampado, esgrimiendo que la apertura pondría en peligro la salud de la población. En Bruselas logré abrir un descampado durante un día, y quien quiso pudo entrar a un solar del centro que normalmente estaba cerrado con llave. En Alcorcón, Madrid, durante una semana abrí un descampa$d^{26}$, un terreno privado al que habitualmente estaba prohibido el acceso; no transformé el terreno ni coloqué nada en su interior, y en él se discutió espontáneamente sobre el pasado y el futuro del lugar ${ }^{27}$. (Fig. 5)

Estas acciones suponen un importante paso en la evolución de su autora: ya no se trata solamente de explorar, de colarse por los resquicios y compartir la experiencia. A partir de este momento se produce una reivindicación explícita del suelo. La intención manifiesta de estos trabajos es "cuestionar el uso del espacio público y la propiedad privada" 28 , siguiendo el "deseo de recuperar un territorio para los ciudadanos" 29 . Durante unos días, parcelas previamente cercadas se convierten en sitios accesibles para cualquiera. Esta apertura altera la urbe de forma perceptible: "abrir un descampado quizás sea el cambio mínimo. Desde luego no es rellenarlo ni construirlo, pero sí que hay un cambio real, en la ciudad y en la calle" 30 .

Las intervenciones nos hacen pensar en una nostalgia de aquellas prácticas conocidas popularmente como de desalambrado, término que aúna diversos tipos de destrucción de aquellas barreras que delimitan la propiedad de la tierra. La propia Almarcegui señala cómo la evolución

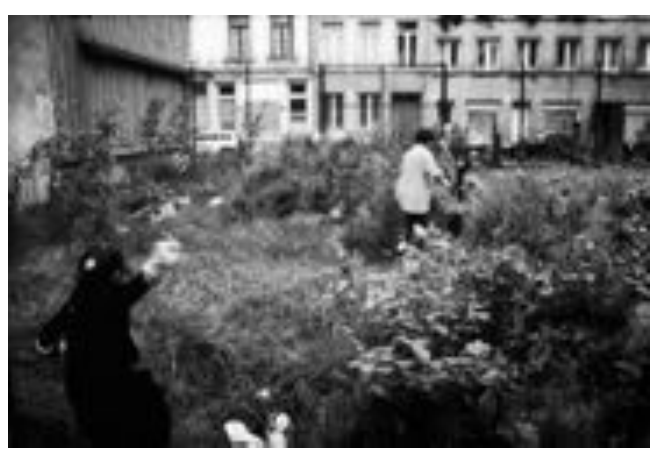

Fig. 5. Abrir un descampado, Bruselas, 2000. 
de sus aperturas avanza en esta dirección ${ }^{31}$ : algunos proyectos posteriores buscan eliminar totalmente la barrera. Después de numerosos intentos frustrados, por primera vez en 2009 la artista logra derribar el muro que cercaba una parcela vacía en la ciudad de Burdeos ${ }^{32}$ (Fig. 6). Un año después, realiza lo propio con un solar de Córdoba, Argentina ${ }^{33}$.

Este gesto de borrar el límite que demarca provoca una impactante alteración del paisaje urbano, pues "hace que el terreno forme parte de la calle" ${ }^{34}$, creando "una repentina situación de naturaleza, de ruina en la acera" ${ }^{35}$.

Frente a la acción más leve de abrir la puerta, derrumbar la barrera resulta mucho más radical y es por tanto más difícil de conseguir: estos trabajos solamente han podido concluirse en dos ocasiones. Ideológicamente, nos encontramos con una obra mucho más fuerte, donde el arte se convierte en una herramienta de desalambrado, que permite acabar con los límites materiales impuestos por la propiedad del suelo ${ }^{36}$. Lara Almarcegui declara su convencimiento de que "un acto pequeño, pero a escala 1:1, a escala real, puede ser significativo" 37 . Sin embargo, conviene recordar que estas alteraciones ciudadanas pactadas, de carácter excepcional, y dentro del medio artístico, constituyen un desalambrado de carácter simbólico.

Las aperturas de la artista son acciones poéticas, esbozos de una posibilidad. La repentina desaparición de la valla que cerca la tierra evoca el resultado de una hipotética acción vandálica, revolucionaria o reformista. En estas intervenciones se configura el boceto apenas sugerido de una ciudad sin muros.

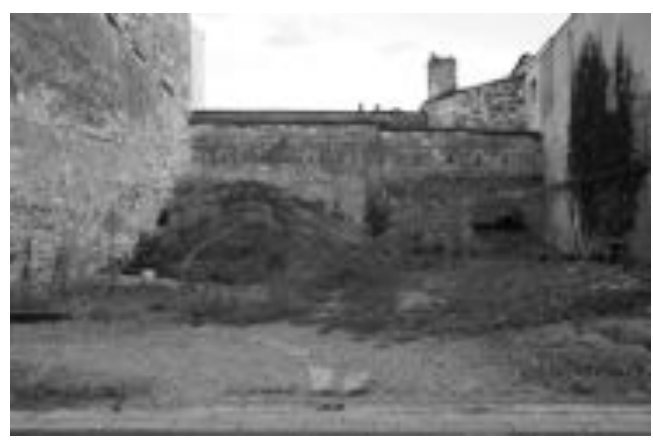

Fig. 6. Terreno abierto Rue Fleche, Burdeos, 2009.

\section{SALVACIONES}

Sucedió como consecuencia del desarroIlo de mi trabajo: primero quise conocer en profundidad un lugar específico; para hacerlo, tuve que encontrar distintas maneras de investigarlo y llegar a conocerlo mejor, lo cual frecuentemente me exigía pasar el mayor tiempo posible en ese lugar. Y la consecuencia lógica de estar mucho en un lugar es reclamarlo u okuparlo ${ }^{38}$.

En 2003 Lara Almarcegui recibe el encargo de hacer una obra permanente para el puerto de Róterdam. La artista decide que su propuesta consista en mantener sin urbanizar un terreno durante al menos quince años. El proyecto, sobriamente, se titula $A$ Wasteland in Rotterdam Harbour 2003-2018 (Un descampado en el puerto de Róterdam 2003-2018). Su autora la describe como "un experimento consistente en dejar un lugar sin definir para que, así, todo en él ocurra por azar, y no correspondiendo a un plan determinado" 39 (Fig. 7). En los años siguientes, logra preservar otros solares, durante lapsos de tiempo que varían. Algunos ejemplos son los de Genk (2004-2014), Matadero de Arganzuela (2005-2006) o Ribera del Ebro (2008).

Los terrenos son elegidos por su singularidad y belleza, y muchos de ellos se sitúan próximos al agua. La intervención de Almarcegui hace que perduren: el terrain vague, generalmente condenado a una desaparición rápida, es artificialmente protegido de la especulación inmobiliaria. Aparece la idea de alterar la temporalidad, convirtiendo en duradero lo efímero.

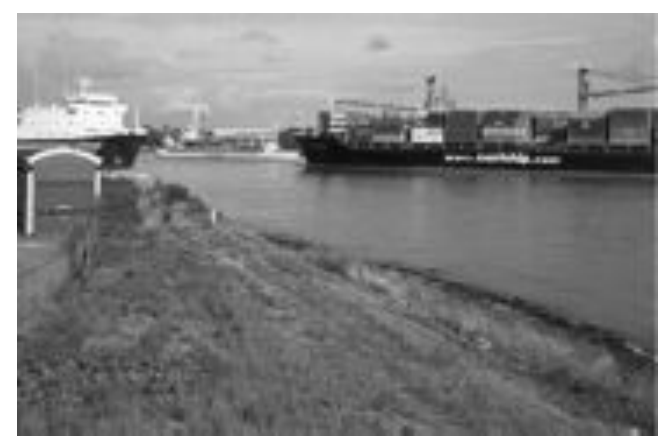

Fig. 7. Un descampado en Róterdam, 2003-2018. 
En la mayoría de los casos, los terrenos preservados pertenecen a la administración pública o, en ocasiones, a fábricas de gran tamaño. La negociación continúa siendo el paso previo a la realización de unos proyectos donde la propiedad se mantiene, alterándose la utilización de las parcelas. Éstas son cedidas en préstamo, como en un extraño alquiler donde la tierra permanece intencionalmente improductiva durante períodos que van de uno a quince años. La artista dice no aspirar a la compra del suelo, pues afirma valorar más el uso que la posesión. Quizás por eso no plantea cambiar la tierra de dueño, sino sólo "protegerla" de ser edificada. El arte se configura como un artificio para preservar el abandono y hacer avanzar la ruina. La naturaleza, aliada con el tiempo, se encarga de crear la obra.

Almarcegui no concibe estos lugares vacíos con un fin social, sino que los entiende como espacios cuya existencia misma resulta primordial, al margen de cualquier utilidad posible. Aunque permanecen abiertos, el grado de accesibilidad de los solares varía según las peculiaridades de cada uno.

En el caso de Róterdam, el "descampado salvado" se sitúa detrás de un edificio, lo cual hace que para llegar hasta él sea necesario llamar a un timbre. Por esta razón, es utilizado fundamentalmente por los empleados que trabajan en el inmueble. Muy diferente es la situación de la zona de exuberante vegetación que Almarcegui preserva en Genk. Entrar es tan sencillo que, para quien no la conozca, la dimensión "artística" pasa totalmente inadvertida frente a lo espectacular de la naturaleza. Los paseantes se encuentran con "una magnifica chopera con praderas y restos de huertas y cabañas abandonadas, árboles frutales e incluso un pequeño arroyo con un puente, canales y terrenos empantanados" 40 . El espacio, sin vallar, está rodeado por un carril para bicicletas que a menudo recorren los excursionistas.

En este tipo de obras tan solo la presencia de discretos carteles indica un supuesto carácter "artístico" del territorio. En ellos se nos plantea la idea de la intervención camuflada: la artista selecciona lugares que ya existían, y no altera en nada su aspecto. El público suele consistir en paseantes, que disfrutan del entorno de manera casual, sin tener conciencia de la condición "ar- tística". Las huellas del arte se disuelven cuando éste se ocupa de conservar en vez de tratar de generar objetos nuevos. Pero esta preservación artificial permite que se generen lugares que, sin ella, no hubieran podido desarrollarse: jardines secretos, jardines salvajes, como el que se encuentra en Genk ${ }^{41}$ (Fig. 8).

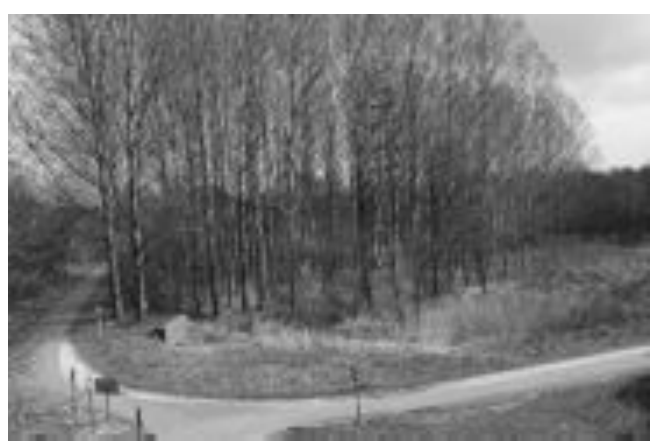

Fig. 8. Un descampado en Genk, 2004-2014.

\section{TAIPEI}

Un lugar salvado especialmente poético es la pequeña isla preservada en Taipei, que en su condición de solar flotante muestra resonancias de la más pura tradición utópica: como en un juego de matrioskas, esta ínsula fluvial se sitúa a su vez dentro de la isla de Taiwán. El proyecto de An empty terrain in the Danshui River, Taipei 2008-2018 (Un terreno vacío en el río Danshui, Taipei 2008-2008), en un primer momento garantiza que este espacio, que nunca ha sido urbanizado, continúe vacío durante al menos diez años más. Posteriores negociaciones logran que esta situación de excepción se prolongue de manera indefinida, es decir, "para siempre".

Generado por la acumulación de deposiciones del río Danshui, este descampado acuático tiene un tamaño de casi tres hectáreas, sujetas a la variación diaria de las mareas y al cambio estacional de las Iluvias. El contorno del territorio es por ello cambiante, difícil de cartografiar. Sus peculiaridades geográficas y las características de su ecosistema son descritas en una pequeña guía, que se edita con ocasión de la Bienal${ }^{42}$. Sin embargo, más allá de un estudio "objetivo", Almarcegui considera que el principal interés del islote estriba en "su potencial evocador"43. 
Fotografías tomadas por la artista nos muestran un paisaje sugestivo, propicio a la contemplación soñadora (Fig. 9) ${ }^{44}$. En ellas, el disparador de la cámara se sitúa en un lugar desde donde la isla adopta la forma de una suerte de flecha torcida. Su vértice más lejano apunta al agua $y$, más allá, hacia la lejana ciudad de la orilla. En estas imágenes el pequeño terreno parece un ente navegador a punto de desembarcar, avanzando quizás hacia el horizonte de los rascacielos.

Al decidir la protección de este espacio, Almarcegui lo convierte en un lugar ajeno al progreso humano, donde reinan los ritmos naturales, pese a que alrededor se sitúen las aceleradas cadencias urbanas. La isla física se hace isla metafórica, territorio a-islado, extraño a la ciudad en la que se inserta. Con el paso de los años, entre la previsible edificación del resto de la zona, desde las dos orillas del río podrá contemplarse, flotando, una pequeña franja de verde. Almarcegui entonces habrá creado una vedutta para aquellos que en Taipei caminen junto al agua. Éstos disfrutarán de la paradoja visual de un peculiar parque flotante, en medio de una metrópoli.

En este tipo de obras, el sentido ecologista resulta explícito ${ }^{45}$. No solamente se otorga un importante papel a la naturaleza, creando una suerte de reserva natural ciudadana, de malas hierbas y alimañas. Frente a la frecuente protección de especies en peligro de extinción que llevan a cabo diversas asociaciones, Lara Almarcegui hace lo propio con aquellos lugares que corren el riesgo de desaparecer. Su labor es la de protección de ecosistemas urbanos amenaza-

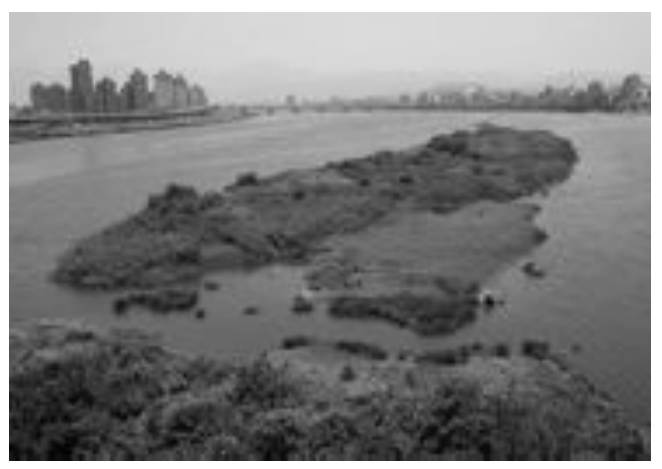

Fig. 9. Un terreno vacío en el río Danshui, 2008-. dos. La reiteración del mismo tipo de proyectos se justifica en este sentido:

los trabajos sobre descampados, sea preservarlos, sea abrirlos, sea escribir sobre ellos me parece que siempre están bien. Cuando veo cuánta construcción hay alrededor cada vez me hacen más falta"46.

Como los demás terrenos vacíos que Almarcegui preserva, la intervención de Danshui contiene una gran afirmación asertiva: el terrain vague, que interesa a la artista "más que ningún discurso" 47 , es un lugar valioso para la ciudad. Un espacio que debe mantenerse tal cual es, permitiendo que desarrolle sus propias dinámicas.

\section{CONCLUSIÓN: URBE GRUYERE}

La presencia del poder invita a escapar de su presencia totalizadora, el confort sedentario llama al nomadismo desprotegido; el orden urbano llama a la indefinición del terrain vague. ${ }^{48}$

Ignasi de Solá Morales es uno de los principales defensores de la especificidad del descampado. En diversos textos, reivindica la necesidad de mantener sus cualidades de vacío y ausencia, sin tratar de insertar los solares dentro de la planificación general de una ciudad basada en lo productivo ${ }^{49}$. Acorde con esta concepción, se encuentre el activismo artístico de Lara Almarcegui.

Para ella, el nivel más básico de su obra se encuentra en la oposición a un urbanismo del control y el consumo. A "la idea de que arquitectos que luego son constructores, urbanistas y, por supuesto, políticos, crean contenedores, y los habitantes de la ciudad los rellenamos con cosas que nos compramos" ${ }^{50}$. A lo largo de su evolución, el trabajo va haciéndose más radical, yendo desde la labor de documentación de las guías al activismo de las aperturas y salvaciones. Más allá de su carácter crítico, este corpus de obras destaca por su carácter propositivo.

Abrir temporalmente un descampado al público supone una reclamación social: una pequeña conquista para la ciudadanía, expan- 
diendo por un momento el espacio público. Los descampados "preservados" crean reservas de naturaleza bastarda, suerte de parques indómitos, garantizando que perdure el vacío en la ciudad. Ambas prácticas contienen una implícita propuesta urbana. De su conjunción se destilaría algo que podemos llamar "anurbanismo", parafraseando la definición de Gordon Matta-Clark, de la "anarquitectura" como el espacio entre los edificios ${ }^{51}$ : el "anurbanismo" de la artista española se ocuparía de la tierra vacía. Para tratar de comprender mejor su proposición, podemos llevar los proyectos de Almarcegui a una ficticia gran escala.

Si se multiplicase la presencia de los descampados abiertos y perdurables, se consolidaría la "ciudad gruyère", cuya densidad quedaría rasgada por una profusión de huecos protegidos. Éstos pasarían a cumplir un papel activo en la metrópoli, configurando islas de libertad según la concepción de Almarcegui. En conjunto, estos solares "liberados" constituirían una especie de fragmentaria tierra común, no necesariamente para el aprovechamiento, tal y como se entendió durante siglos el commons en Europa: este sería, en cambio, como un territorio para la naturaleza salvaje y la utilización humana no reglada. Un conjunto de lugares donde los ciudadanos podrían refugiarse de la ciudad capitalista.

En esta propuesta de zonas autónomas ${ }^{52}$ percibimos una cierta herencia del pensamiento anárquico. Almarcegui considera lógico que la tierra sea de propiedad colectiva. Sin ser militante, simpatiza con algunas prácticas vinculadas al anarquismo, corriente con la que se identifica fundamentalmente a través de la figura precursora y heterodoxa de Henry David Thoreau. Cuando habla sobre el uso ideal de los descampados, la artista se refiere al disfrute común, pues para ella el terrain vague debería ser accesible al uso de quien quiera entrar en él:

Pueden ser los vecinos, puede ser el visitante, el turista que está agobiado de tanto monumento $y$ se quiere fumar un cigarro tranquilo... Puede ser la loca que da de comer a los gatos, alguien que quiera volar una cometa... En fin [alli podría realizarse] toda la actividad que no tiene espacio en el resto de la ciudad ${ }^{53}$.

En su obra, el descampado invierte su sentido originario. Terrenos que generalmente surgen como espacios residuales en los procesos de especulación inmobiliaria se convierten en un freno y en una alternativa a estos mismos procesos. El abrir (o eliminar) las verjas que impiden el uso del descampado suspende por un momento la infranqueable división entre el espacio público y el privado. El proteger algunos solares permitiendo su desarrollo, ofrece un paréntesis espacial en la oposición binaria entre la planificación absoluta del asfalto y la aparente indeterminación de la naturaleza salvaje. Así, las intervenciones de la artista resuelven simbólicamente contradicciones urbanas que han generado el propio hueco urbano, y borran temporalmente conflictos que parecen irresolubles.

Los descampados intervenidos por Almarcegui pretenden ser un refugio. Una tierra de promisión dispersa, frente a aquella ciudad de especuladores que no nos pertenece. La creadora no parece tener en cuenta la marginalidad y la delincuencia que podrían instalarse en sus terrenos francos. Su obra busca garantizar que entre empresas, comercios y viviendas se sitúe el terrain vague. Una tierra de nadie que es terreno de todos: zona abierta a los ciudadanos libres y a la naturaleza sin domesticar. 


\section{NOTAS}

1 I. de Solà-Morales, "Urbanité Intersticielle", Inter Art Actuel, 61, 1995, pp. 27-29. Citado en F. Careri, Walkscapes, Gustavo Gili, Barcelona, 2009, p. 40.

${ }^{2}$ I. de Solá Morales, Presente y futuros. La arquitectura en las ciudades, COAC/CCB/Actar, Barcelona, 1996, pp. 10-23.

Accesible en http://www. urbanoperu.com/filesitos/Presente_y_ Futuros \% 5B 1 \% 5D \% 20Sola.pdf [Consultado: 19/01/2011].

${ }^{3}$ Esta situación se hace especialmente patente en España, donde han surgido plataformas como $V$ de $V$ ivienda, desde donde se afirma que en nuestro país la vivienda es "la más cara del mundo" en relación con los salarios. Véase: http://www.vdevivienda. net [Consultado: 30/03/2011]

${ }^{4}$ Algunos ejemplos serían el arquitecto Santiago Cirugeda o los artistas Jan Kopp y Rahel Hegnauer.

${ }^{5}$ Entrevista personal inédita de la autora con Lara Almarcegui, Madrid, 15.02.2011.

${ }^{6}$ La artista, en su voluntad de no "intervenir" coincide con el colectivo de arquitectos italianos Stalker, osservatorio nomade. Véase la página web de estos últimos: http://www. osservatorionomade.net [Consultado: 7/03/2011]

7 "[U]n ready-made es algo "ya hecho" o previamente fabricado. El artista no crea, en el sentido tradicional, sino que elige entre los objetos del universo industrial o (en menor medida) natural". Cfr. J. A. Ramírez, Duchamp. El amor y la muerte, incluso, Siruela, Madrid, 1993. En su selección de espacios, Lara Almarcegui continúa una tradición que, partiendo del dadaísmo, pasa por el object trouvé surrealista. A través de sus textos, podemos ver como su obra acusa la influencia de lo "insólito cotidiano" del surrealismo, y su visión extrañada del entorno. Véase, a título de ejemplo, L. Aragon, Le paysan du Paris, Gallimard, París, 2001.

${ }^{8}$ Respecto a la percepción estética de paisajes poco "heroicos" tenemos en España el precedente de la llamada Escuela de Vallecas. Acerca de la misma, véase E. Carmona Mato, "La escuela de Vallecas, naturaleza, arte puro y atmósfera surreal", J. M. Bonet (ed.),
El surrealismo y sus imágenes, Fundación Cultural Mapfre Vida, Madrid, 2002, pp. 257-280. Lara Almarcegui, sin embargo, está más influenciada por otras corrientes internacionales, como son el land art norteamericano y europeo, que trabaja de forma directa con el paisaje real. Según la propia artista recalca, para ella resulta fundamental el trabajo de Robert Smithson sobre lo que él llama los Monumentos de Passaic.

Esta obra de 1967 se enuncia en varios frentes: por una parte está el viaje de Smithson por la periferia de Nueva Jersey, quedando fascinado por un entorno de abandono. Por otra, se encuentra el texto donde el propio creador describe este recorrido, el artículo "The Monuments of Passaic", originalmente publicado en Art Forum. De manera paralela, en la galería Dwan se exhiben algunos documentos artísticos resultantes de la "odisea suburbana": un mapa en negativo de la zona y veinticuatro fotografías en blanco y negro. Finalmente, se encuentra la incitación a la visita del lugar, que se desprende de la exposición y del texto. Lara Almarcegui va a retomar la idea de una documentación que busca precipitar el viaje hacia lugares poco valorados, que se encuentran marcados por el vacío. Hemos consultado R. Smithson, "A Tour of the Monuments of Passaic", en Robert Smithson: El Paisaje Entrópico, Una retrospectiva 1960-1973 (Valencia, IVAM, 1993), M. Gilchrist y J. Lingwood (eds.), Valencia, 1993, pp. 74-77 y, también, F. Careri, op. cit., pp.156-168.

${ }^{9}$ En 1963 se fundan como Ateliers 63 en Haarlem, con la intención de ofrecer una alternativa a la educación artística masificada. Desde 1992 se sitúa en Ámsterdam, y alberga aproximadamente veinte estudiantes, a los que se ofrece un estudio propio durante un máximo de dos años. En su elenco histórico de profesores cuenta con artistas como Jan Dibbets, mientras que personajes como Joep van Lieshout han sido alumnos del centro. Véase http://www.de-ateliers.nl/ [Consultado: 20/01/2011]. Respecto a la obra de este último creador, véase J. Ramírez Blanco, "La ciudad desmontable", Lars, Cultura y ciudad, 21, 2010, pp. 39-43.

10 L. Almarcegui, Guide to non delimitated rooms at de Ateliers, Áms- terdam, 1997. Tenemos que agradecer a la artista el envío de diversas guías, entre las cuales se encuentra esta obra auto editada, que hoy resulta extremadamente difícil de encontrar.

${ }^{11}$ Conviene recordar la tradición artística de la apropiación de formatos propios del turismo para proponer una aprehensión distinta de la ciudad. Un ejemplo temprano es la visita dadá a la iglesia de Saint Julien le Pauvre el 14 de abril de 1921. El género de la guía es empleado en diversas ocasiones a lo largo de la historia del arte, destacando la Description raisonée de Paris (Descripción razonada de París) del situacionista Jacques Fillon (1955) y la Guide Psychogéografique de Paris (Guía psicogeográfica de París), mapa desplegable de un París descompuesto, realizado por Guy Debord (1957). Véase F. Careri, op. cit., pp. 68-118. El precedente más claro de las guías de Almarcegui se encuentra sin embargo en el ya mencionado trabajo sobre los llamados "Monumentos de Passaic" de Robert Smithson. Gilchrist y Lingwood (eds.), op. cit.

12 L. Almarcegui, Wastelands Map Amsterdam. A Guide to the Empty Sites of the City, Stedelijk Museum Bureau, Ámsterdam, 1999.

${ }^{13}$ Entrevista personal inédita, op. cit.

${ }^{14}$ Ibid.

15 L. Almarcegui, Guide to undefined places in Lund, Lund Sverige, Lunds Konsthall, Lund, 2005.

${ }^{16}$ L. Almarcegui, Guía de los terrenos baldíos de São Paulo, Fundación Bienal de São Paulo, São Paulo, 2006.

${ }^{17} \mathrm{~L}$. Almarcegui, Guía de Descampados de la Ría de Bilbao, Sala Rekalde de Bilbao, Bilbao, 2008.

$18 \mathrm{~L}$. Almarcegui, Guide to the Wastelands of the Lea Valley. 12 Empty Spaces Await the London Olympics, Barbican Art Gallery, Londres, 2009.

19 L. Almarcegui, Guide to the Wastelands of Flushing River Queens, New York City, Ludlow 38, European Kunsthalle Collogne, Goethe-Institut New York, Nueva York, 2010.

${ }^{20}$ Muchas de estas guías pueden verse en la exposición Lara Almarcegui. Madrid subterráneo, comisariada por Manuel Segade en el Centro de Arte Dos de Mayo (Móstoles, 28.0628.10.2012). 
${ }^{21}$ En ese sentido, su obra enlaza con el trabajo del artista alemán Hans Haacke y, en especial, la reciente instalación "Castillos en el aire" (2012), que da título a su exposición en el Museo Nacional Centro de Arte Reina Sofía (Madrid, 14.02-23.06-2012, comisariada por Manuel Borja Villel). En ella, Haacke documenta y mapea los complejos residenciales de una periferia madrileña que, tras el estallido de la burbuja inmobiliaria, se queda a medio construir.

${ }^{22}$ Entrevista personal inédita, op. cit.

${ }^{23}$ Smithson, op.cit.

${ }^{24}$ H. D. Thoreau, Walden, Avenel Books, Londres, 1985 (primera publicación en 1854). En la obra de Almarcegui encontramos numerosos puntos de conexión con el célebre libro. Algunos serían la idealización de lo "salvaje", la observación atenta del entorno. También estarían el placer por la autoconstrucción y la voluntad del experimentar con la autosuficiencia que Almarcegui ha desarrollado en proyectos como Construyendo mi huerta urbana (Róterdam 1999-2000), Tres semanas restaurando una cabaña de jardin (Falsburgo, 2000), o La autoconstrucción en Saint Nazaire (Saint Nazaire, 2002). cit.

${ }^{25}$ Entrevista personal inédita, op.

${ }^{26}$ Elena Vozmediano describe esta última obra de la siguiente manera "Lara Almárcegui acotó hace unos meses una pequeña parcela que quedará como reserva natural, testigo de lo que el solar fue en sus años de abandono. Unos frondosos plátanos y multitud de malas hierbas serán estudiados por un botánico, y el Ayuntamiento se ha comprometido a mantener la acotación al menos un año". E. Vozmediano, "Testmadrid. El matadero como laboratorio artístico", El Cultural, 01.12.2005, accesible en versión digital: http:// www.elcultural.es/version_papel/ ARTE/16013/Testmadrid_el_Matadero_como_laboratorio_artistico [Consultado: 10 de febrero 2011]

${ }^{27}$ L. Almarcegui, Lara Almarcegui: exposición documental: demoliciones, descampados, huertos urbanos, Centro Párraga, Murcia, 2003, p. 11.
$28 \mathrm{lbid}$.

${ }^{29} \mathrm{Ibid}$.

${ }^{30}$ Entrevista personal inédita, op. cit.

${ }^{31}$ Durante nuestra extensa entrevista con la artista, le hablamos de esta forma de interpretar su trabajo. Pese a no haber pensado en ello, se mostró complacida con la metáfora, añadiendo que en sus proyectos más recientes se hace más explícita. [Entrevista personal inédita, op. cit.].

${ }^{32}$ La obra fue realizada en el contexto de Evento, Bienal de Burdeos, Burdeos, 2009.

${ }^{33}$ Este trabajo tuvo lugar en el marco de Afuera. Arte en Espacios públicos. Muestra internacional de arte contemporáneo en la ciudad de Córdoba, Córdoba, Argentina, 2010.

${ }^{34}$ Entrevista personal inédita, op. cit.

${ }^{35} \mathrm{Ibid}$.

${ }^{36} \mathrm{Ibid}$.

${ }^{37}$ M. Stjerstedt, "A Conversation between Lara Almarcegui and Mats Stjerstedt", Index-The Swedish Contemporary Art Foundation, octubre 2003, en http://www.indexfoundation.se/ scripts/Page. asp? id=348 [Consultado: 17/01/2011].

${ }^{38}$ M. Stjerstedt, op. cit.

${ }^{39} \mathrm{~L}$. Almarcegui, "Demoliciones, huertas urbanas, descampados", Boletín $C F+S, 38 / 39,2006$, en http://habitat.aq.upm.es/boletin/n38/alalm.html [Consultado: 23/02/2011]

40 L. Almarcegui, "Demoliciones...", op. cit.

${ }^{41}$ Lara Almarcegui desarrolla más explícitamente la idea del jardín secreto con su proyecto International Garden Festival 2004, que fue presentado en la Bienal de Liverpool del 2004. En este vídeo, documentaba las parcelas abandonadas del Festival Internacional de Jardinería de 1984. Véase http:///iverpoolbiennial.adatabase.org/index.php/ objectui/type,vra.vrawork/id, 18091 [Consultado: 12/03/2011]

${ }^{42} \mathrm{~L}$. Almarcegui, An empty terrain in the Danshui River, Taipei 2008-2018, Taipei Biennialle, Taipei, 2008. En este pequeño libro se describe la geografía física del terreno y se analiza su ecosis- tema. En la isla conviven plantas que resisten las inundaciones y arbustos que crecen en las zonas más secas. En este entorno habitan numerosos insectos, pájaros y animales resistentes como ratas o serpientes.

${ }^{43} \mathrm{lbid}, \mathrm{s} / \mathrm{p}$.

${ }^{44}$ Diversas imágenes de la isla fueron proyectadas como diapositivas en la sala de exposiciones de la Bienal de Taipei de 2008. Junto a las proyecciones, se situaba una mesa de madera con ejemplares gratuitos de la guía de la isla.

${ }^{45}$ Relacionado con esta idea está el proyecto en que la artista desarrolla una huerta urbana, Construyendo mi huerta urbana (volkstuin), Róterdam 1999-2002. cit. .

${ }^{46}$ Entrevista personal inédita, op.

47 J. Hontoria, "Lara Almarcegui, «los objetos no me interesan, me obsesionan los lugares»", El Cultural, 2008, accesible en su edición digital: http://www.elcultural.es/articulo_imp.aspx?id=22949 [Consultado: 03/05/2011]

48 I. de Solà-Morales, "Urbanité Intersticielle", op. cit.

49 Véase I. de Solà-Morales, Presente $y$ futuros..., op. cit.

${ }^{50}$ Entrevista personal inédita, op. cit.

${ }^{51}$ En 1974 Matta Clark forma el grupo Anarchitecture, El interés de Matta Clark por los "vacíos metafóricos, huecos, espacios sobrantes, lugares no aprovechados" ya se hace patente en una entrevista que mantiene con Liza Bear (Avalanche, diciembre 1974 , p. 34). Citado en D. Moriente, Poéticas arquitectónicas del arte contemporáneo, Madrid, Cátedra 2010, p. 36 .

${ }^{52}$ Recordemos al respecto las Zonas Temporalmente Autónomas de Hakim Bey. Véase H. Bey, TAZ: Zona Temporalmente Autónoma, anarquía ontológica, terrorismo poético, Tálasa, Madrid, 1996.

${ }^{53}$ Entrevista personal inédita, op. cit. 